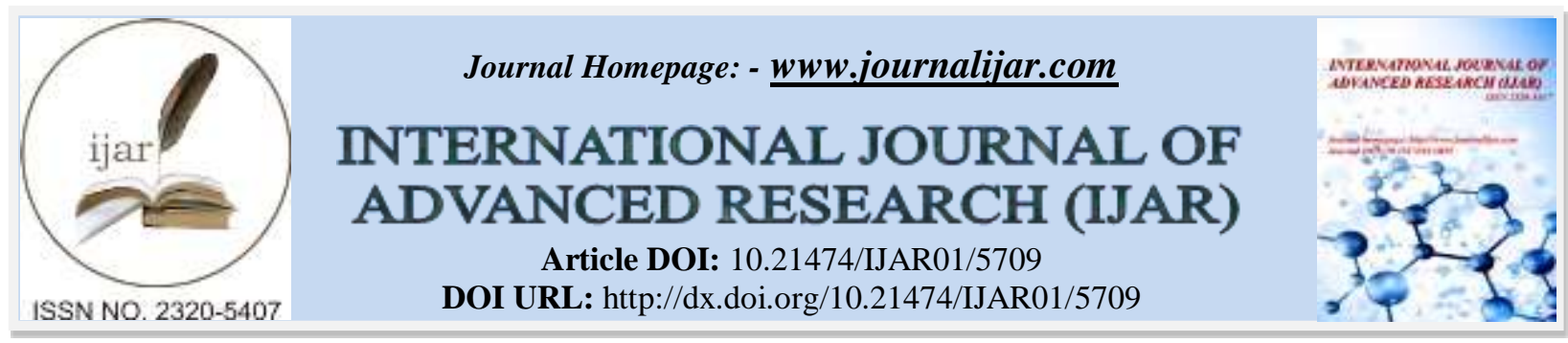

RESEARCH ARTICLE

\title{
THE THERAPEUTIC ROLE OF VITAMIN E OR ZINC AND THEIR MIXTURE SUPPLEMENTATION ON SOME HEAVY METALS-INDUCED TESTICULAR FUNCTIONS INJURIES IN MALE RATS.
}

\author{
Marwan A. Ibrahim. \\ Biology Department, College of Science / Majmaah University, K.S.A.
}

\section{Manuscript Info}

Manuscript History

Received: 24 August 2017

Final Accepted: 26 September 2017

Published: October 2017

Key words:

Cadmium; Lead; Mercury; Testicular functions; Vitamin E; Zinc.

\section{Abstract}

Background: Toxic heavy metals in water, air and soil are global problems that are a growing threat to humanity. Heavy metals are widely distributed in the environment and some of them occur in food, water, air and tissues even in the absence of occupational exposure.

Aim: To investigate the antioxidant and protective influences of vitamin $\mathrm{E}$ and/or zinc on some heavy metals (lead, cadmium and mercury) induced oxidative stress and testicular injuries in male rats.

Results: Results showed that exposure to lead, cadmium or/and mercury causes damage or alterations in the testicular functions in male albino rats. On the other hand, vitamin $\mathrm{E}$ or/and zinc administration lessened or cured these damages and repaired the destruction which occurred because of exposure to these toxic substances.

Conclusion: heavy metals stimulated different hazardous effects leading to testicular dysfunction in male rats, and the supplementation of vitamin E or/and zinc play(s) an important role to minimize and reduce the harmful effects of heavy metal exposure. These improvements are attributed to the antioxidant functions of vitamin $\mathrm{E}$ and zinc. In addition, suggestions for further studies were recommended.

Copy Right, IJAR, 2017, All rights reserved.

\section{Introduction:-}

The rate of pollution with heavy metals compounds is increased with civilization. The animal body can store some heavy metals that enter the body and excrete it without adverse health effects, but when the animal is over exposed either accidentally or occupationally to high level of heavy metals, symptoms of heavy metals toxicity result. The total body burden of heavy metals includes (i) a rapidly exchangeable pool in blood and soft tissue (like reproductive organs), (ii) an intermediate pool of exchangeable heavy metals in skin and muscles and (iii) a more stable pool in the skeleton [1]. The build-up of heavy metals in soils and waters continues to create serious global health concerns, as these metals cannot be degraded into non-toxic forms, but persist in the ecosystem. Contamination of the environment with heavy metals has increased beyond the recommended limit and is detrimental to all life forms [2].

Although heavy metals are found naturally in the earth, they become concentrated as a result of human activities and can enter plant, animal and human tissues through inhalation, diet and manual handling. They can interfere with cellular components. Cadmium, lead, and mercury are among the top 10 chemicals of major public concern to the 
World Health Organization (WHO). Some of their sources include atmospheric deposition, waste disposal, fertilizer, pesticide application, industry and nuclear waste [3].

Unlike organic contaminants, heavy metals cannot be broken down by chemical or biological processes. Hence, they can only be transformed into less toxic species. The preponderances of heavy metals are poisonous at little applications and are able of inflowing the food chain, where they collected and inflict damage to living animals. All metals have the probability to display destructive effects at higher concentrations and the poisonousness of each metal depends on the quantity available to animals, the immersed amount, the path and the time of contact. Owing to the harmful effects of these metals, there are rising ecological and public health worries, and a consequential necessity for rise awareness in order to remediate the heavy metal contaminated atmosphere $[3,4]$.

Lead is undoubtedly one of the oldest occupational toxins and evidence of lead poisoning can be found dating back to Roman times. As, manufacturing lead fabrication started at least five thousand years ago, it is likely that outbursts of lead toxicity happened from this time. Despite serious study, there is still enthusiastic discussion about the lethal effects of lead, both from low-level exposure in the overall inhabitants due to ecological contamination and notable usage of lead in paint, pipes and from exposure in the occupational setting [5].

Mercury was used as a bright red pigment by the Palaeolithic painters of 30,000 years ago to decorate caves in Spain and France. Mercury is a universal component in the environment producing oxidative stress in the exposed persons leading to tissue destruction. Its pollution and poisonousness has posed a severe threat to human well-being. The discharge of $\mathrm{Hg}$ from dental amalgamation dominates exposure to mineral $\mathrm{Hg}$ and may have an acceptable hazard between the overall people. Human contact to $\mathrm{Hg}$ can happen by breathing, ingestion and depletion through food chain. Adverse effects of metals on human reproduction and development continue to be a demanding challenge for researchers [6].

On the other hand, cadmium is a modern toxic metal. It was discovered as an element only in (1817), and industrial use was minor until about 60 years ago, but now it is a very important metal with many applications. Due to its corrosive less properties, its chief usage is in coating or galvanizing. It is similarly used as a pigment for paints and plastics and as a cathode material for Ni-Cd batteries. Cadmium is a by-product of zinc and lead mining and smelting, which are important sources of environmental pollution [7].

In general, lead, Mercury and cadmium produce their toxicity by forming complexes or ligands with organic compounds. These modified biological molecules lose their ability to function properly, and result in the malfunction or death of the affected cells. The most common groups involved in ligand formation are oxygen, sulphur, and nitrogen. When lead, Mercury and cadmium bind to these groups, they may inactive important enzyme systems, or affect protein structure [6]; [8].

Antioxidants reduce the effect of dangerous oxidants by binding together with these harmful molecules, thereby decreasing their destructive power. Antioxidants can also help repair the damage already sustained by cells. [9]

Vitamin $\mathrm{E}$ and zinc are two of many antioxidants which can block some of the damage caused by free radicals, and can also help reduced the damage to the body which caused by toxic chemicals and pollutants such as heavy metals $[10,11]$.

Zinc is an essential mineral that is found in almost every cell. It stimulates the activity of approximately 100 enzymes, which are substances that promote biochemical reactions in our bodies. Zinc supports immune system, needed for wound healing, helps maintain sense of taste, smell and is required for DNA synthesis. Zinc also supports normal growth and development during pregnancy, childhood and adolescence. [10]

Vitamin $\mathrm{E}$ is a vital factor in human nutrition and considered the greatest effective lipo-soluble antioxidant present in the biological system. It is well-known to have been confirmed beneficial in certain disease courses. Because of the health problems induced by many environmental pollutants, much effort has been expended in evaluating the relative antioxidant potency of vitamin E [11-14]. Till the first decade of the twenty-one century, there is no information regarding the effect of vitamin $\mathrm{E}$ on the testicular toxicities induced by a mixture of heavy metals $(\mathrm{Pb}$, $\mathrm{Hg}, \mathrm{Cd}$ and $\mathrm{Cu}$ ) exposure in mice or other mammals [15]. Furthermore, precise action of vitamin $\mathrm{E}$ and zinc is not fully elucidated and the interaction between vitamin $\mathrm{E}$ and zinc with testicular cells still requires further study. 
Therefore, the present study is designed to investigate the possibility that the administration of vitamin E and zinc would have a beneficial effect on these heavy metals-induced testicular injuries.

\section{Materials and Methods:-}

\section{1- Animals}

140 Male albino rats Rattus rattus, weighing 100-120 g, were obtained from the serum and antigen laboratories (Helwan). The animals were housed throughout the experiment in metallic cages and allowed to acclimatize to laboratory environment for ten days to avoid any complications along the period of the experiment. Animals were maintained under controlled conditions of temperature at $28 \pm 2{ }^{\circ} \mathrm{C}$ and $50 \%$ relative humidity and normal photoperiod (12-12 h light-dark cycles) and received food and water ad-libitum with new supplies offered daily.

\section{Evaluation of lead, cadmium and Mercury levels in mullet:-}

In the current experiment a comparison was occurred between the levels of lead, cadmium and mercury in Fringe-lip Mullet (Crenimugil crenilabis) which was fished from South Sinai as a control area and Suez Canal as a polluted area. The levels of lead, cadmium and mercury in Mullet of control area are 53.47, 10.18 and 4.54 ppm compared to 187.04, 59.12 and 19.86 ppm in Mullet of polluted area respectively. The Suez Canal fish were polluted by many heavy metals due to the pass of the ships and throw the sewage of industrial factories which surround Suez Canal area. Mullet is the most common fish considered by many people as their main source of animal's protein.

According to these results the studied rats were received $190 \mathrm{mg}$ of lead, $60 \mathrm{mg}$ of cadmium and $20 \mathrm{mg}$ of mercury per kilogram diet for one month to follow the chronic damage of these heavy metals (lead, cadmium \& mercury) on the testicular function tests.

\section{Experimentation:-}

This study included two experiments; the first one carried out on four groups of rats $(\mathrm{n}=5)$ to follow up the changes occurred in the testicular function tests as a result of exposure to lead, cadmium and mercury. Rats of the first group served as controls and received normal diet without any heavy metals. Rats of the second group received $190 \mathrm{ppm}$ elemental of $\mathrm{Pb}$ in their diet. Animals of the third group received $60 \mathrm{ppm}$ elemental of $\mathrm{Cd}$ in their food. Group four received 20 ppm of mercury elemental of $\mathrm{Hg}$ in their food for 30 days.

The second experiment done on three main groups (40 rats) each of them divided into four subgroups to investigate the prophylactic effects of administration of vitamin $\mathrm{E}$ or zinc and their mixture on the testicular function tests of toxicated rats. Rats of the first group served as recovery group i.e. rats were allowed a 15 and/or 30 days periods without any treatment. Rats of the second group is a vitamin E treated group, i.e. rats were intraperitoneally injected with vitamin $\mathrm{E}$ at a dose of $50 \mathrm{IU} / \mathrm{kg}$ body weight, BW, according to [15] three times weekly for 15 and 30 days. Animals of the third group are zinc treated group, i.e. rats were received 40.5 ppm elemental zinc according to [16] for 15 and 30 days. Group four is a mixture group i.e. rats were received both antioxidants at the same doses of the $2^{\text {nd }}$ and $3^{\text {rd }}$ groups for 15 and 30 days.

Five rats from each subgroup were randomly selected at 15 and 30 days, experimental duration. Autopsies were performed under total anesthesia with diethyl ether hence testis and blood samples were collected. Blood sample left to clot and sera separated for measurement of total protein, total lipids, testosterone, estradiol, and FSH \& LH levels using suitable kits reagents [17], [18], [19], [20] and [21] respectively.

Determination of reduced GSH content and SOD activity of tissue samples were determined by the method of [17] and [22] respectively.

To exam the normalities and abnormalities of sperms, smear of mature spermatozoa, collected from the cauda epididymis were stained with haematoxylin and eosin [23].

\section{Statistical analysis:-}

The calculations and statistical analysis were carried out using the IBM SPSS software (version 20.0, SPSS Inc.). All data were represented as mean \pm standard error (SE). Data were subjected to one-way analysis of variance (ANOVA) followed by Student's t-test. Statistical probability of $\mathrm{P}<0.05$ was considered to be significant [24], [25]. 


\section{Results:-}

This investigation was conducted to elucidate the therapeutic role of zinc or vitamin E and their mixture supplementation in terms of reducing and correction the toxic effects of lead, cadmium \& mercury on testicular function testes. In general, normal control rats in the presents study were mostly active during the day, calm by night time, had good appetite and kept their fur clean while toxicated rat groups were inactive, lost their appetite and had dirty fur.

From the inspection of the data presented in table $(1)$, a significant $(\mathrm{p}<0.05)$ decrease in total number of sperm and total number of normal sperm. The lowest mean values for both parameters were noted in rats treated with mercury. The decrease in total and normal number of sperm were accompanied with a significant $(\mathrm{p}<0.05)$ elevation in total number of abnormal sperm. The per-cent of these increments were 47.71, 86.56 and 100.43 respectively.

Table (1): - The mean value of testicular function tests as well as serum hormonal assays in all treated rat groups

\begin{tabular}{|c|c|c|c|c|c|}
\hline \multicolumn{2}{|c|}{ Groups } & Control & Lead & Cadmium & Mercury \\
\hline \multirow{3}{*}{ Total no. of sperm } & Mean & 962.36 & 672.53 & 592.11 & 564.93 \\
\hline & $\pm \mathrm{SE}$ & \pm 3.714 & \pm 3.131 & \pm 2.884 & \pm 3.348 \\
\hline & $\%$ & & -30.1165884 & -38.4731286 & -41.2974355 \\
\hline \multirow{3}{*}{ Total no. of normal sperm } & Mean & 879.42 & 564.13 & 443.86 & 432.26 \\
\hline & $\pm \mathrm{SE}$ & \pm 3.662 & \pm 2.901 & \pm 2.704 & \pm 2.278 \\
\hline & $\%$ & & -35.8520388 & -49.5280981 & -50.8471493 \\
\hline \multirow{3}{*}{ Total no. of abnormal sperm } & Mean & 69.43 & 102.56 & 129.53 & 139.16 \\
\hline & $\pm \mathrm{SE}$ & \pm 1.127 & \pm 1.344 & \pm 1.612 & \pm 1.703 \\
\hline & $\%$ & & 47.71712516 & 86.5620049 & 100.4320899 \\
\hline \multirow{3}{*}{ Total protein (mg / g) } & Mean & 3.72 & 3.11 & 2.71 & 2.66 \\
\hline & $\pm \mathrm{SE}$ & \pm 0.077 & \pm 0.059 & \pm 0.047 & \pm 0.041 \\
\hline & $\%$ & & -16.3978495 & -27.1505376 & -28.4946237 \\
\hline \multirow{3}{*}{ Total lipids (mg / g) } & Mean & 4.02 & 4.49 & 4.85 & 5.01 \\
\hline & $\pm \mathrm{SE}$ & \pm 0.096 & \pm 0.113 & \pm 0.138 & \pm 0.149 \\
\hline & $\%$ & & 11.69154229 & 20.64676617 & 24.62686567 \\
\hline \multirow{3}{*}{ Testosterone (ng / ml) } & Mean & 2.49 & 1.86 & 1.57 & 1.48 \\
\hline & $\pm \mathrm{SE}$ & \pm 0.075 & \pm 0.063 & \pm 0.054 & \pm 0.053 \\
\hline & $\%$ & & -25.3012048 & -36.9477912 & -40.562249 \\
\hline \multirow{3}{*}{ Estradiol (ng / ml) } & Mean & 9.33 & 14.23 & 16.92 & 19.38 \\
\hline & $\pm \mathrm{SE}$ & \pm 0.153 & \pm 0.229 & \pm 0.289 & \pm 0.326 \\
\hline & $\%$ & & 52.5187567 & 81.35048232 & 107.7170418 \\
\hline \multirow{3}{*}{ FSH (mIU / ml) } & Mean & 2.68 & 3.11 & 3.47 & 3.91 \\
\hline & $\pm \mathrm{SE}$ & \pm 0.089 & \pm 0.108 & \pm 0.116 & \pm 0.148 \\
\hline & $\%$ & & 16.04477612 & 29.47761194 & 45.89552239 \\
\hline \multirow{3}{*}{ LH (mIU / ml) } & Mean & 3.48 & 4.83 & 4.99 & 5.19 \\
\hline & $\pm \mathrm{SE}$ & \pm 0.094 & \pm 0.112 & \pm 0.137 & \pm 0.155 \\
\hline & $\%$ & & 38.79310345 & 43.3908046 & 49.13793103 \\
\hline \multirow{3}{*}{ Testis GSH (lmol / g tissue) } & Mean & 9.69 & 7.38 & 6.87 & 7.29 \\
\hline & $\pm \mathrm{SE}$ & \pm 0.94 & \pm 1.03 & \pm 0.962 & \pm 1.01 \\
\hline & $\%$ & & -23.8390093 & -29.1021672 & -24.7678019 \\
\hline \multirow{3}{*}{ Testis SOD (U / mg tissue) } & Mean & 139.93 & 104.02 & 102.09 & 103.52 \\
\hline & $\pm \mathrm{SE}$ & \pm 11.33 & \pm 6.22 & \pm 5.92 & \pm 5.76 \\
\hline & $\%$ & & -25.6628314 & -27.0420925 & -26.0201529 \\
\hline
\end{tabular}

On the contrary, administration of lead, cadmium \& mercury to the animals led to a significant $(\mathrm{p}<0.05)$ decrease in total protein compared to the normal control rats. The percentages of decline were 16.39, 27.15 and 28.49 respectively. 
Also, supplementation of lead, cadmium \& mercury to rats caused an increment in the total lipid. The mean values of total lipid reached to $4.49 \pm 0.113,4.85 \pm 0.138$ and $5.01 \pm 0.149 \mathrm{mg} / \mathrm{g}$ in toxicated rats respectively.

On detecting serum testosterone level using the data tabulated in table (1). It is recognized that rats treated with lead, cadmium \& mercury revealed a significant $(\mathrm{p}<0.05)$ decrease in serum testosterone as compared to the corresponding normal control rats.

In relation to the control rats, a significant $(\mathrm{p}<0.05)$ increase in oestradiol $(\mathrm{E} 2)$, follicular stimulating hormone (FSH) and luteinizing hormone (LH) were reported in rats treated with lead, cadmium and mercury. The percent of these increases reached to 52.51, 81.35 and 107.71 for E2, 16.04, 29.47 and 45.89 for FSH and 38.79, 43.39 and 49.13 for $\mathrm{LH}$ respectively.

On detecting Testis GSH and SOD level using the data tabulated in table (1). It is recognized that rats treated with lead, cadmium and mercury revealed a significant $(\mathrm{p}<0.05)$ decrease in Testis GSH and SOD level as compared to the corresponding normal control rats.

On the second experiment data recorded for total number of sperm and total numbers of normal sperm are presented by figure (1) among all experimental groups. Toxicated recovery rats elucidating an elevation in both total number of sperm and total number of normal sperm throughout 30 days experimental period compared to those which left for 15 days.

In response to administration of vitamin $\mathrm{E}$, toxicated rats manifested a slight increase in total number of sperm and normal sperm within the course of experimental period as compared to the recovery toxicated animal's groups. This amelioration effect was persisted among toxicated rats belonging to zinc treatment. Whereas total number of sperm and normal sperm mean values at any interval of estimation were higher in general than the recovery animals group reaching its highest value at the last interval compared to recovery groups. Accountable change was occurred in the double course of treatment (vitamin $\mathrm{E}$ and zinc) as compared to the other antioxidants groups.

Figure (1) recorded the total number of abnormal sperm of toxicated animals from all groups during the investigation period. Toxicated rats left for recovery period showed a decline in their mean values which become more pronounced proportional to the progress of time. Although, the supplementation of vitamin E to toxicated rats caused a significant decrease of the total number of abnormal sperm. Moreover, addition of zinc alone or couple with vitamin $E$ to toxicated rats postulated that the mixture of vitamin $E$ and zinc was the most potent group in its lowering in comparison to the other corresponding animals.

Supplementation of vitamin $\mathrm{E}$ alone induced a significant $(\mathrm{p}<0.05)$ increase in the testicular total protein in lead and cadmium toxicated rats throughout the whole experimental period. On the other hand, after treatment with zinc alone or in combination with vitamin E remarkable changes in testicular total protein was occurred in all toxicated rat's groups.

On contrary there is a slight decrease in testicular total lipid in toxicated groups during the course of the study after recovery period and the supplementation of vitamin $\mathrm{E}$, zinc or their mixture induced a significant $(\mathrm{p}<0.05)$ decrease in the testicular total lipid in toxicated rats throughout the whole experimental period.

The treatment of lead, cadmium and mercury toxicated rats with antioxidants (vitamin E, zinc or their mixture) recorded significant $(\mathrm{p}<0.05)$ increase in the level of serum testosterone. On contrary the treatment of lead, cadmium or mercury toxicated rats with antioxidants (vitamin E, zinc or their mixture) recorded significant $(\mathrm{p}<0.05)$ decrease in the level of serum estradiol.

It is recognized a decrease in serum F.S.H. \& L.H. levels in toxicated groups during the study after recovery period. Treatment by vitamin E or zinc managed to induce a gradual depression in serum F.S.H. \& L.H. in all toxicated rats commencing from the first interval and reaching its lowest value at the last interval of estimation. This effect persisted among toxicated rats belonging to combined therapy of vitamin $\mathrm{E}$ in combination with zinc. Meanwhile treatment of lead, cadmium and mercury toxicated rats with antioxidants (vitamin E, zinc or their mixture) recorded significant $(\mathrm{p}<0.05)$ increase in the level of testis GSH and SOD. 

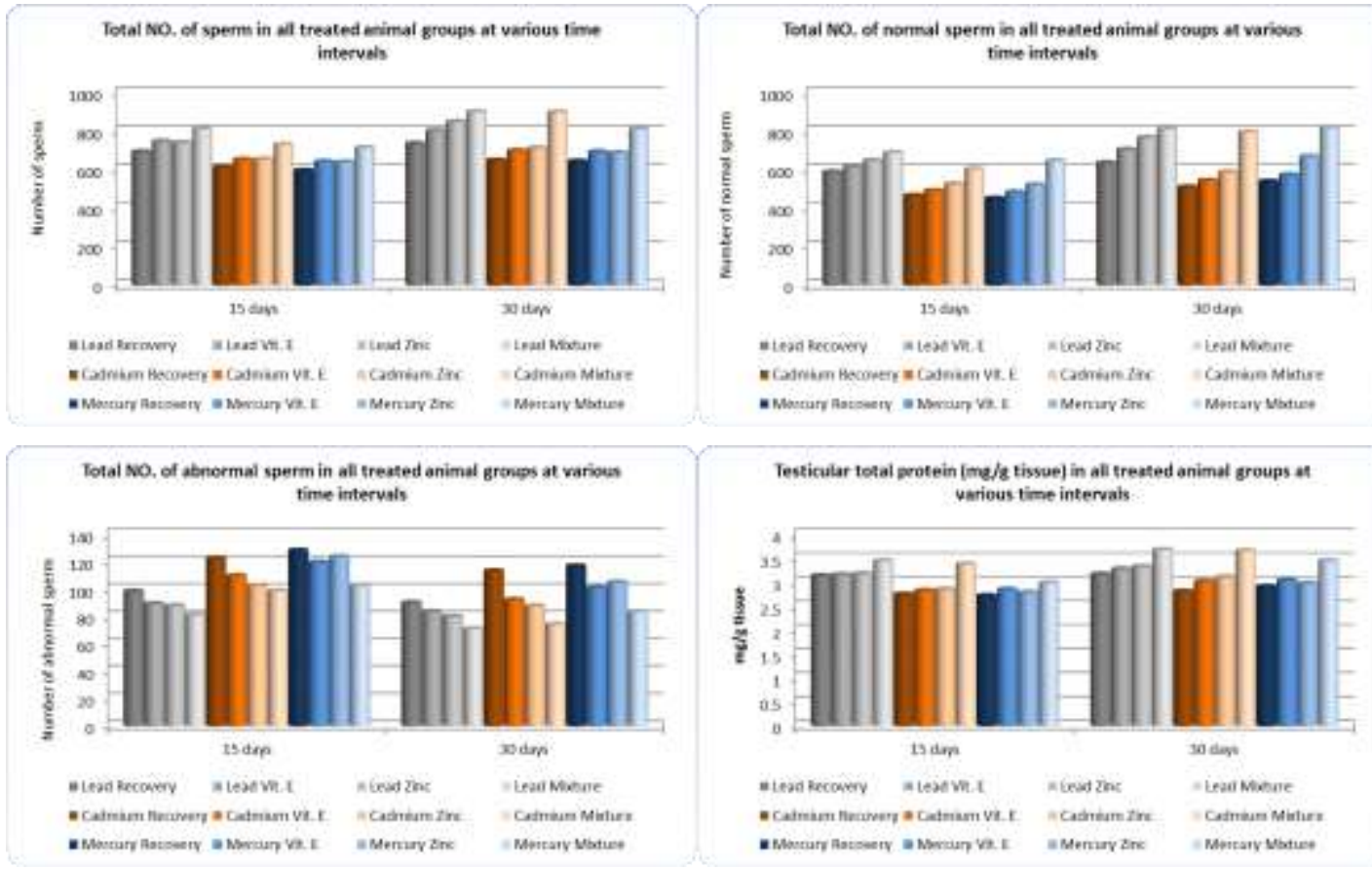

Testicular fotal lipid (mg/g tissue) in all treated animal groups a warious time intervais

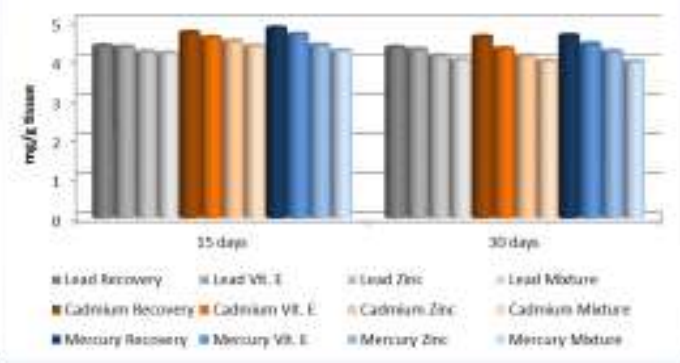

Serum testosterone level (re $/ \mathrm{mll}$ in all tremed animal goups at warious time intervais
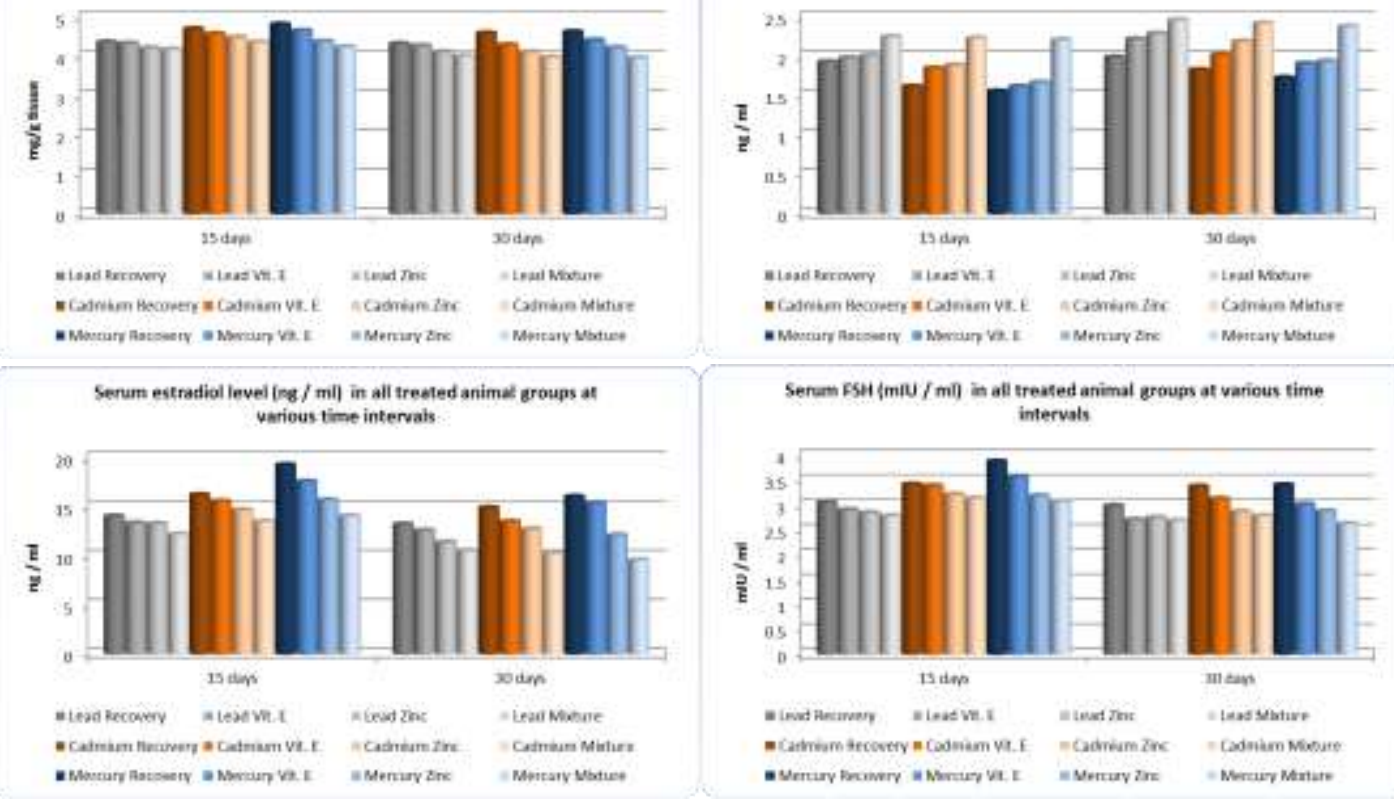

Senum LA $(\mathrm{mll} / \mathrm{ml})$ in all treated animal goups at various time intervals
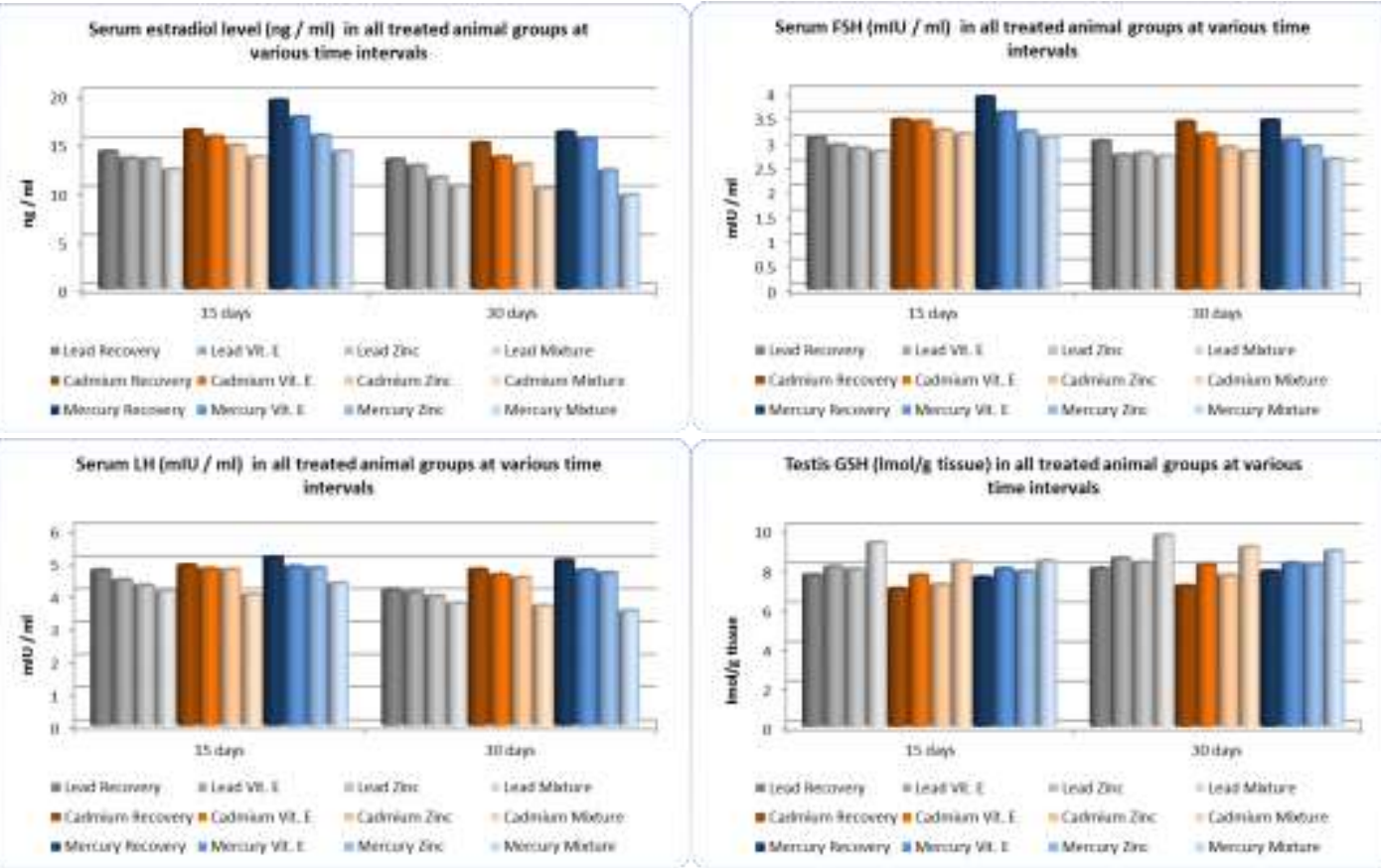


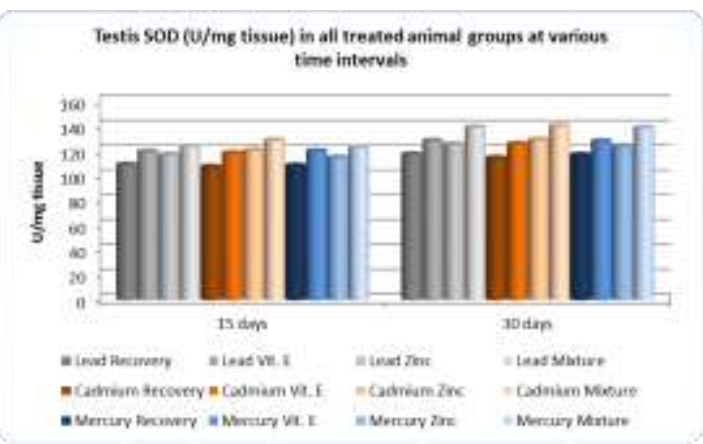

Figure (1): - The mean value of testicular function tests as well as serum hormonal assays in all treated animal groups at various time intervals

\section{Discussion:-}

It is well known that heavy metals are widely distributed in environment and most of them can cause physiological and biochemical disorders. Animals are exposed to these metals from several sources, including contaminated air, water, soil and food. Therefore, the evaluation of toxic potentials of metals is important for the risk assessment of human beings ordinarily exposed to these substances [26].

Fertility in humans, like that in experimental animals, is susceptible to toxic effects from environmental and/or industrial chemicals. Infertility is a problem of increasing concern in several industrialized countries. [27] suggested methods for detecting occupational causes of male infertility. The decrease in sperm quality purportedly having occurred over the past 50 years [28].

Different scientific studies indicated that the degree of toxic manifestation of different metals depends on dose, duration, route of administration and other physiological factors, especially nutrition [26]. The present study indicated that the administration of heavy metals to rats produced testicular damage, which led to spermatogenic arrest. Similar observations were noted in experimental animals exposed to heavy metals [29], [30], and [31]. The potential toxicity of heavy metals caused alteration in sperm morphology, count, motility as well as biochemical disruptions of enzymes and hormones [26].

Lead toxicity is manifest in male reproductive system by deposition of $\mathrm{Pb}$ in testes, epididymis, vas deferens, seminal vesicle and seminal ejaculate. Lead has a hostile result on sperm count and slow the movement of a living sperm. Furthermore, motility as well as prolonged inactivity of sperm melting both in exposed individual and investigational animals was detected after $\mathrm{Pb}$ exposure [32].

Mercury is a spermato- fetotoxic agent. Mercury exhibited structural alteration of testicular tissue along with biochemical change. The control testis of albino rat showed sharp localization of ACPase, ATPpase and ALKPase in PTM, spermatogeic cell and Leydig cell membrane [33]. While mercury and its complexes, methyl mercury chloride, affected these membranes bound hydrolytic enzymes in rats it caused in severe reduction of these enzymes, co-related with advanced deterioration of peritubular membrane. Mercury also affected the structural and functional breakdown of these enzymes due to its great attraction towards the enzyme's (SH) group [34]. The prominent features of $\mathrm{Hg}$ induced toxicity are: (i) depletion and clogging of different spermatogenic cells, (ii) presence of pyknotic or karyotectic pachytene nuclei, (iii) absence of nuclear chromatin at stage XII in dividing cells, (iv) absence of noticeable lumen and (v) presence of vacuolated early elongated spermatid along with dispositioning of acrosome. The intensity of damage is directly proportional to the duration of exposure [35].

Cadmium can cause marked morphological changes in the form of swelling, congestion, haemorrhage and necrosis in testes of Sprague-Dawley rats [36]. Great amount of Cd contact produced a quick testicular edema, haemorrhage and necrosis. Cd exerted harmful effect on the vascular construction of testis that may be the consequence of varying degrees of $\mathrm{Cd}$ induced ischemia. Degeneration of testicular tissue after different doses of Cd exposure caused rupture of blood vessels [37]. The decrease in serum testosterone levels observed in heavy metals treated rats may reflect direct effects of the metal at the testis as this metal accumulates in this tissue. Similar alteration in testosterone concentrations have been reported [38], [39], the study indicating a disruption of the regulatory 
mechanism of the hypothalamic-pituitary axis. In addition, administration of vitamin E, zinc or their mixture might have relieved the reduction of testosterone and/or may have triggered their synthesis that in turn attenuated the oxidative damage caused by cadmium or its metabolites. The final step in the biosynthesis of testosterone is the reduction of androstenedione by the enzyme, 17-ketosteroid reductase [40]. The significant decrease of this enzyme in heavy metals intoxicated rats interprets the decreased level of testosterone in such group. However, administration of vitamin E, zinc or their mixture increased the level of this enzyme and subsequently increased testosterone level in vitamin $\mathrm{E}$, zinc or their mixture treated group, this is according to the fact that 17-ketosteroid reductase enzyme is protein in nature, that damaged like other proteins by heavy metals and treatment with vitamin E, zinc or their mixture attenuates the damage effect on the tissue protein content and hence on the enzyme [41].

In the current study, a significant decrease in both total number and normal number of rat spermatic counts after exposed to lead, cadmium or mercury, while their malformed number increased significantly as it tabulated in (table1). Moreover, testicular total protein content was decreased in all toxicated rat groups with a significant elevation in testicular total lipid content.

As a result of toxicity of both $\mathrm{Pb}, \mathrm{Cd}$ or $\mathrm{Hg}$ a significant disturbance was occurred in the hormonal status in all treated animal's groups. This disturbance was represented by a significant decrease in the serum testosterone level and a significant increase in the serum FSH, LH and E2 levels. These testicular dysfunction and hormonal disturbance may be attributed to the toxicity of $\mathrm{Pb}$ or $\mathrm{Cd}$ and $\mathrm{Hg}$ on the hypothalamic-pituitary- testis axis (HTPTA) by the elevation of FSH and LH levels due to a remarkable damage in both Sertoli and Leydig cells.

In rats treated with heavy metals there were significant decreases in the levels of GSH and SOD in testis tissues. Glutathione, a tripeptide present in most cells, is responsible for hydrophilic xenobiotics conjugation. GSH serves many vital physiological functions including protection of cells from reactive oxygen species (ROS), detoxification of exogenous compounds, and amino acid transport [42]. Sulphydryl group of glutathione is essential for its antioxidant activity against some forms of ROS in cells [43]. Much of the pathology is associated with the decrease in intracellular GSH concentration [44]. Therefore, GSH concentration is important for survival of the cells. The most important protective mechanism for free radical scavenging and inhibition of electrophilic xenobiotics attack on cellular macromolecules involves tripeptide glutathione [43]. Owing to nucleophilic thiol group, it may purify substances in one of three techniques: (i) combined catalysed by glutathione-S-transferases (GST), (ii) biochemical response with a reactive metabolite to produce a conjugate and (iii) contribute of proton or hydrogen atom to sensitive metabolites or free radicals. Concerning the role of glutathione in the defence against oxidative stress and detoxification of xenobiotics, its availability in the reduced procedure (GSH) may be an important factor in care of health. It has been recognized in numerous different animal models, as well as in humans, that a reduction in GSH concentration may be related with aging and pathogenesis of countless diseases [45], [46].

Superoxide dismutase (SODs) belong to a group of antioxidant enzymes that catalyse the dismutation of superoxide to produce hydrogen peroxide and oxygen [47]. SOD is essentially a protective enzyme which scavenges the superoxide ions produced as cellular by-products during oxidative stress [48]. Its decreased activity can lead to adverse effects because superoxide anions are extremely toxic and may accumulate in the cells. Numerous studies point to that heavy metals doing as catalysts in the oxidative reactions of biological macromolecules consequently the poisonousness with these metals might be owing to oxidative tissue injury [49], [50].

Arbitrating from these result, they are in harmony and confirmed through [51], [52] and [53]. The authors attributed these results to the testicular atrophy and interstitial cell hyperplasia as a result of heavy metals exposure. Also, [52] explained these damage to the disturbance in serum dehydroepiandrosterone sulphate (DHEA-S) level and elevation in serum activity of prostatic acid phosphatase (PAP) and testicular gamma glutamyl transpeptidase (testicular-GTP) activity as a result to heavy metal exposure.

Free radical production and lipid peroxidation are potentially important mediators in testicular physiology and toxicology. The cytochrome $\mathrm{P}_{450}$ enzymes of the steroiogenic pathway are known to produce free radicals. The effects of heavy metals on hepatic testosterone metabolism have been studied by [54]. They utilized testosterone metabolism as a probe to characterize heavy metals effects on GH- secretion pattern. Male-specific hydroxylation occurs at position 2-alpha and 16-alpha catalyzed by the cytochrome $\mathrm{P}_{450}$ isozyme CYP2C11. CYP2C expression and activity is under the absolute regulation of the male-specific pattern of GH secretion [55-59]. 
In the current study, it is of interest to ratify that vitamin $\mathrm{E}$ or zinc treatments improved the seminal picture and decreased the testicular dysfunction with enhancement in the sexual hormones dependent on time of treatments. The maximum improvements were occurred in the toxicated animal groups which received the both antioxidants (Vitamin $\mathrm{E}$ and zinc). This correction was dependent on time of treatment (figure 1). These results may be due to the ability of vitamin $\mathrm{E}$ and zinc to act as free radical scavengers resulting in the cell membrane stabilization with decreasing the formation of lipid peroxidation. Accordingly, these decreased the injury, damage and atrophy in the testis tissues.

Vitamin E allows free radicals to abstract a hydrogen atom from the antioxidant molecule rather than from polyunsaturated fatty acids, thus breaking the chain of free radical reactions, the resulting antioxidant radicals being a relatively unreactive species [60]. In many studies vitamin E neutralizes lipid peroxidation and unsaturated membrane lipids because of its oxygen scavenging effect [61], [62] Therefore vitamin E supplementation sufficient to protect the organism from toxic agent and free radical damage is a time-consuming process.

[63] examined the effect of both pre- and post-treatment of vitamin $\mathrm{E}$ on $\mathrm{Hg}$ induced acute toxicity in rats. $\mathrm{Hg}$ resulted in oxidative injury and metallothionein mRNA expression together with alterations in tissue histology and accumulation of $\mathrm{Hg}$ in the body organs. The improving potential of vitamin $\mathrm{E}$ was detected in mercury administered rats. Furthermore, they specified that their results indicate that vitamin $\mathrm{E}$ offers whole protection from mercury poisonousness in the liver with both pre- and post-treatments. Moreover, they recommended that post-treatment with vitamin $\mathrm{E}$ might be more useful than pre- treatment in mercury intoxication.

[64] showed that Cd can harshly destroy testicular tissues and disturb spermatogenesis in rats. Vitamin E cure can protect testicular tissue and reserve spermatogenesis from the harmful effects of Cd nevertheless its effectiveness is reliant on the amount of Cd exposed. [65] stated that vitamin E can improve regular food intake, body weight gain and feed efficiency ratio; reduced $\mathrm{Pb}$ levels in serum and tissues as well as reduced urea and creatinine levels in $\mathrm{Pb}$ intoxicated rats. Cure with vitamin E was very effective in the inhibition of oxidative injury. Furthermore, they concluded that vitamin $\mathrm{E}$ pretreatment incompletely lessens $\mathrm{Pb}$-induced oxidative stress by changing antioxidant enzymes. [66] and [67] established the efficiency of vitamin $\mathrm{E}$ in decreasing oxidative stress in Cd -treated animals and proposed that declines in increased lipid peroxidation due to $\mathrm{Cd}$ poisonousness may be an significant factor in the action of vitamin E. [68] presented that the exposure to $\mathrm{Cd}$ produced marked elevation in the level of lipid peroxidation and a decline in SOD, glutathione peroxidase (GSH-Px) and CAT activities complemented by an upsurge in the rate of hemoglobin autoxidation in Swiss albino rats. Moreover, they verified that the cure with vitamin E significantly reduced the alterations caused by $\mathrm{Cd}$ exposure in all examined parameters. Furthermore, they suggested that these consequences indicate that alterations caused by $\mathrm{Cd}$ or $\mathrm{Pb}$ relate to free radical's generation and used antioxidants effectively to protect against $\mathrm{Cd} \& \mathrm{~Pb}$ intoxication.

Both cadmium and zinc are divalent. So, cadmium can be substituted zinc in the reaction and tissue. This fact leads to deficiency in the level of zinc after exposure to cadmium pollution. This data supported by [59]. The authors reported that zinc deficiency impaired the synthesis of testosterone in the testis of Zn-deficient rats and this impairment was reflected on the level of blood testosterone.

Zinc deficiency causes several malformations and has deleterious effects on several functions, particularly on the male genital organs. [69] reported that hypogonadism is noted in Zn-deficient males of all species studied. It appears that male accessory sex gland is also dependent on zinc for their normal function. Since, relatively high concentrations of zinc are found in seminal plasma and prostate gland in particular. Where, its uptake of zinc is stimulated by testosterone, which regulates prostate activity [70]. All these findings suggest that zinc plays an important role in male reproductive function. [71] examined stained cross sections made in testes derived from boars fed a zinc deficient diet for 7 - 8 weeks, found that the Leydig cells (which is responsible for synthesis and secretion of testosterone in testis) were smaller, their cytoplasm stained contained more fat droplets than those removed from the testes of boars fed on a zinc-sufficient diet. These results indicated that zinc has a direct effect on Leydig cells, consequently on testicular function by its possible involvement in the production of testosterone. In man, [72] reported that serum testosterone concentrations are sensitive to short term zinc depletion in young men.

As the result of $\mathrm{Pb}$ or $\mathrm{Cd}$ and their mixture exposure, testicular total lipid was decreased. Thus, these results confirmed the earlier statement which reported that, zinc deficiency affects lipid metabolism in rats. Several assumptions were proposed to explain the mechanisms whereby zinc deficiency could alter lipid metabolism in $\mathrm{Zn}$ - 
deficient animals, but they are not quite uniform. [73] stated that the type, of dietary fat can modify the effect of zinc deficiency on lipid fractions and testosterone level in plasma.

Another explanation of the elevated levels of testicular total lipid of heavy metal rat's groups is based on the increased susceptibility of those animals to enhance oxidative stress and lipid per-oxidation [74]. This per-oxidation became more pronounced in Zn- deficient rats fed linseed oil than those fed olive oil [75]. In contrary, [76] and [77] reported that zinc deficiency in rats causes a prominent impairment in the intestinal absorption of lipid and based on the well-known facts about the poor appetite developed in zinc deficient animals, accordingly, lower amount they eat and lesser weight they gain than controls [78]. Under these circumstances, it may be acceptable assumption that animals (fed ad-libitum) in their straggle to maintain their life they require and mobilize lipids from tissue toward blood to meet their energy needs.

The result of this study proved that zinc intake may have an improve effect on testicular total lipid, as it is shown in (fig 1). This result may be attributed to the enhancement in the thyroid function. In study carried out by [79], significant declines in the levels of $\mathrm{T}_{3}$ and $\mathrm{T}_{4}$ were found in the sera of both ad-libitium $\mathrm{Zn}$-deficient rats and $\mathrm{Zn}$ sufficient, calorie restricted rats as compared with control rats received $\mathrm{Zn}$-sufficient diet ad-libitum. But in $\mathrm{Zn}-$ deficiency, lower $\mathrm{T}_{3}$ was recorded than its comparable level in caloric restriction state. This result suggests that maintenance of serum $T_{3}$ levels may be zinc dependent. It is possible that zinc is necessary for extrathyroidal $\mathrm{T}_{3}$ to $\mathrm{T}_{4}$ conversion.

\section{Conclusion \& Recommendations:-}

In conclusion, it may be substantiated that exposure to heavy metals $(\mathrm{Pb}, \mathrm{Cd}$ or/and $\mathrm{Hg}$ ) stimulated different hazardous effects leading to damage, and testicular dysfunction in male rats. Furthermore, the supplementation of vitamin $\mathrm{E}$ or/and zinc play(s) an important role to minimize and reduce the harmful effects of heavy metal exposure. These improvements are attributed to the antioxidant functions of vitamin $\mathrm{E}$ and zinc.

Accordingly, this work recommended that an environment preservation law must be strictly enforced, particularly in crowded residential areas. This is mainly achieved by getting rid of the sources of the industrial fumes that contain lead, cadmium or/and mercury which are causes of various disease. Generally, factories and especially heavy factories should be moved outside the residential areas and surrounding by highest trees and plants for making natural shield to stop or reduce the pollutant fumes.

Also, this investigation recommended the beneficial supplementation of daily diet intake with vitamin $\mathrm{E}$ and zinc due to their effective roles in building the general body resistance parameters and immunity system. They also aid in decreasing the destructive and harmful effects caused by $\mathrm{Pb}, \mathrm{Cd}$ or/and $\mathrm{Hg}$ in the testicular function. The maximum amelioration effects occurred when the toxicated rats treated with both antioxidants (vitamin $\mathrm{E}$ and zinc). These results may be attributed to synergistic effects of vitamin $\mathrm{E}$ and zinc, also to the improvements in the physical and biochemical properties of them to work together for reducing destructive and harmful effects which caused by $\mathrm{Pb}$, $\mathrm{Cd}$ or/and $\mathrm{Hg}$. This correction was dependent on time of treatment.

\section{References:-}

1. Abosede, O. A. (2017): Review on heavy metals contamination in the environment; European Journal of Earth and Environment, Vol. 4, No. 1 pp 1-6.

2. Deng, W., Li, X., An, Z., Yang, L. (2016): The occurrence and sources of heavy metal contamination in peri urban and smelting contaminated sites in Baoji, China. Environmental Monitoring and Assessment 188:251.

3. Ayangbenro, A. S. and Babalola, O. (2017): A New Strategy for Heavy Metal Polluted Environments: A Review of Microbial Biosorbents; Int. J. Environ. Res. Public Health 14, 94.

4. Mani, D.; Kumar, C. (2014): Biotechnological advances in bioremediation of heavy metals contaminated ecosystems: An overview with special reference to phytoremediation. Int. J. Environ. Sci. Technol., 11, 843872.

5. Gidlow, D. A. (2004): In-depth review Lead toxicity. Occupational Medicine; 54:76 - 81.

6. J. S. Coursey, D. J. Schwab, J. J. Tsai, and R. A. Dragoset, Atomic Weights and Isotopic Compositions (version 4.1), 2015, National Institute of Standards and Technology, Gaithersburg, MD, accessed November 2016.

7. Gunnarsson, D.; Svensson, M.; Selstam, G. Nordberg, G. (2004): Pronounced induction of testicular PGF2 $\alpha$ and suppression of testosterone by cadmium - prevention by zinc. Toxicology 200, 49-58. 
8. Poo. Chinthana and T. Ananthi (2012): Protective Effect of Solanum nigrum and Solanum trilobatum Aqueous Leaf Extract on Lead Induced Neurotoxicity in Albino mice. J. Chem. Pharm. Res., 4(1):72-74.

9. Khalid Rahman (2007): Studies on free radicals, antioxidants, and co-factors. Clin Interv Aging.; 2(2): 219236.

10. Institute of Medicine. Food and Nutrition Board. Dietary Reference Intakes for Vitamin A, Vitamin K, Arsenic, Boron, Chromium, Copper, Iodine, Iron, Manganese, Molybdenum, Nickel, Silicon, Vanadium, and Zinc. National Academy Press. Washington, DC, 2001.

11. Beytut, E., Yuce, A., Kamiloglu, N.N., Aksakal, M., 2003. Role of dietary vitamin E in cadmium-induced oxidative damage in rabbit's blood, liver and kidneys. Int. J. Vitam. Nutr. Res. 73, 351-355.

12. Pillai, A., Gupta, S., 2005. Antioxidant enzyme activity and lipid peroxidation in liver of female rats co-exposed to lead and cadmium: effects of vitamin E and Mn+2 Free Radic. Res. 39, 707-712.

13. Jalili, Sh., Ilkhanipour, M., Heydari, R., Farshid, A.A., Salehi, S., 2007. The effects of vitamin E on endosulfaninduced oxidative stress in rat heart. Pak. J. Nutr. 6, 375-380.

14. El-Gharieb, M.A., El-Masry, T.A., Emara, A.M., Hashem, M.A., (2010): Potential hepatoprotective effects of vitamin $\mathrm{E}$ and Nigella sativa oil on hepatotoxicity induced by chronic exposure to malathion in human and male albino rats. Toxicol. Environ.Chem. 92, 391-407.

15. Atef M. Al-Attar (2011): Antioxidant effect of vitamin E treatment on some heavy metals-induced renal and testicular injuries in male mice. Saudi J Biol Sci.; 18(1): 63-72.

16. Krieger, R. (ed.). Handbook of Pesticide Toxicology. Volume 2, 2nd ed. 2001. Academic Press, San Diego, California., p. 1365.

17. Sedlak J and Lindsay R H. (1986): Estimation of total protein-bound and non-protein sulfhydryl groups in tissue with Ellman`s reagent. Anal. Biochem., 24(25): 192-205.

18. Zollner, N. and Kirsch, K.Z. (1962): Determination of total lipids colour-metrically using phospho-vanillin reagent in acidic media. Ges. Exp. Med., 135: 545.

19. Jaffe, B.M. and Behrman, N.R. (1974): Methods of Hormone Radioimmunoassay ed. Academic Press.

20. Bergquist C., Nillius S. J. and Wide L., (1983): Human gonadotrophin therapy: 1, Serum estradiol and progesterone patterns during conceptual cycles. Fertil.Steril., 39:761-5.

21. Beastall GH and others. Assays for follicle stimulating hormone and luteinizing hormone: Guidelines for the Provision of a Clinical Biochemistry Service. Ann Clin Biochem. 24:246-62.

22. Asada K, Takahashi M, Nagate M (1974) Assay and inhibitors of spinach superoxide dismutase. Agric Biol Chem 38: 471-473.

23. Marchlewicz, M.; Protasouicki, M.; Rozewicka, L.; Piasecka, M. and Laszczynska, M. (1993): Effect of longterm exposure to lead on testis and epididymis in rats. Folia-Histochem. Cytobiol. 31 (2), 55-62.

24. Steel RG, and Torrie JH. (1960): "Principles and procedures of statistics." McGraw Hill, Book company, Inc., New York.

25. Avram G. (1964): "Quantitative Data." In: Biostatistics: An Introductory text. Chapter 2, page 53 \& 63. The MacMillan Company, New York, Collier MacMillan limited, London.

26. Roy Chowdhury A. (2009): Recent advances in heavy metals induced effect on male reproductive function-A retrospective. Al Ameen J. Med. Sci., 2: 37-42.

27. Levine, R.J. (1983): Methods for detecting occupational causes of male infertility. Scand J Work Environ Health 9:371-376.

28. Carlsen, E.; Giwercman, A.; Keiding, N. and Skakkeback, E. N. (1992): Evidence for decreasing quality of semen during the past 50 years. British Medical Journal 305, 609-613.

29. Obianime A W, and Roberts I I. (2009): Antioxidants, cadmium-induced toxicity, serum biochemical and the histological abnormalities of the kidney and testes of the male Wistar rats. Niger. J. Physiol. Sci., 24: 177-185.

30. Yasmina M, and Abdennour C. (2008): Influence of vitamin C on testicular functions of domestic rabbit Oryctolagus cuniculus under mercury exposure. Eur. J. Sci. Res., 22: 197-204.

31. Almansour M I. (2009): Histological alterations induced by lead in the testes of the quail Coturnix coturnix. Res. J. Environ. Toxicol. 3, 24-30.

32. Madhavi D, Devi K R, Rao K K, and Reddy P P. (2007): Modulating effect of Phyllanthus fruit extract against lead genotoxicity in germ cells of mice. J. Environ. Biol., 28: 115-117.

33. Roy Chowdhury A, and Vachhrajani K D. (1997): Methylmercury induced effect on seminiferous PTM in rats. Indian J. Physiol. Allied Sci., 51: 9-15.

34. Al-Madani W A, Siddiqi N J, and Alhomida A. S. (2009): Renal toxicity of mercuric chloride at different time intervals in rats. Biochem. Insights, 2: 37-45. 
35. Vachhrajani, K.D., Roy Chowdhury, A., Dutta, K.K., 1990. Testicular toxicity of methylmercury. Reprod. Toxicol. 6, 355-361.

36. El-Shahat A, Gabr A, Meki A, and Mehana E. (2009): Altered testicular morphology and oxidative stress induced by cadmium in experimental rats and protective effect of simultaneous green tea extract. Int. J. Morphol., 27: 757-764.

37. Yang H S, Han DK, Kim J R, and Sim J C. (2006): Effects of atocopherol on cadmium-induced toxicity in rat testis and spermatogenesis. J. Korean Med. Sci., 21: 445-451.

38. Devy A, Khan B A, and Kumar M. (2006): Cadmium chloride induced histopathological and biochemical changes in the testes of adult albino rats. Toxicol. Int., 13: 61-64.

39. Lafuente A, Màrquez N, Pérez-Lorenzo M et al. (2001): Cadmium effects on hypothalamicpituitarytesticular axis in male rats. Experimental biology and Medicine, 226: 605-11.

40. Granner D K, Murray R K, Granner D L et al. (2002): Hormones of the gonads in: Harper 's Biochemistry (24th Ed), Prentice-Hall International, Inc. pp., 566-80

41. Kojima-Yuasa A, Umeda K, Ohkita T, Opare Kennedy D et al. (2005): Role of reactive oxygen species in zinc deficiency-induced hepatic stellate cell activation. Free Radic. Biol. Med., 39: 631-640.

42. Mendoza-Co' zatl D, Loza-Tavera H, Herna' ndez-Navarro A et al. (2005): Sulfur assimilation and glutathione metabolism under cadmium stress in yeast, protists and plants. FEMS Microbiol. Rev., 29: 653-671.

43. Cnubben N H P, Rietjens I M C, Wortelboer H, Van Zanden J, and Van Bladeren P J. (2001): The interplay of glutathione-related processes in antioxidant defense. Environ. Toxicol. Pharmacol., 10: 141-152.

44. Rouach H, Fataccioli V, Gentil M et al. (1997): Effect of chronic ethanol feeding on lipid peroxidation and protein oxidation in relation to liver pathology. Hepatology, 25: 351-355.

45. Lomaestro B M, and Malone M. (1995): Glutathione in health and disease: pharmacotherapeutic issues. Ann. Pharmacother., 29: 1263-1273.

46. Dro"ge W, Gross A, and Hack V. (1997): Role of cysteine and glutathione in HIV infection and cancer cachexia: therapeutic intervention with N-acetylcysteine. Adv. Pharmacol., 38: 581-600.

47. Johnson WT, Johnson L A. K, Henry C, and Lukaski H C. (2005): Serum superoxide dismutase 3 (extracellular superoxide dismutase) activity is a sensitive indicator of $\mathrm{Cu}$ status in rats. J. Nutr. Biochem., 16: 682-692.

48. Pushpakiran G, Mahalakshmi K, and Anuradha C V. (2004): Taurine restores ethanolinduced depletion of antioxidants and attenuates oxidative stress in rat tissues. Amino Acids, 27: 91-96.

49. Leonard S, Harris G K, and Shi X L. (2004): Metal-induced oxidative stress and signal transduction. Free Radic. Biol. Med., 37: 1921-1942.

50. Flora S J, Mittal M, and Mehta A. (2008): Heavy metal induced oxidative stress and its possible reversal by chelation therapy. Indian J. Med. Res., 128: 501-523.

51. Kubo, K.; Saito, M.; Tadakora, T. and Maekawa, A. (1998): Dietary docosahexaenoic acid does not promote liquid peroxidation in rat tissue to the extent expected from peroxidizability index of the lipids. BiosciBiotechnol-Biochem. 62 (9): 1698 - 1706.

52. Godeas, C.; Tramei, F; Sandri, G. and Panfili, E. (1999): Rat testis mitochondrial phospholipids hydroperoxide glutathione peroxidase does not protect endogenous vitamin $\mathrm{E}$ against $\mathrm{Fe} 2+$ induced (lipo) peroxidation. Biochem. Mol. Med. 58(2): 221 - 227.

53. Yassein, A.A. (2004): Lead toxicity and lead chelation 2,3 dimercaptosuccinic acid (DMSA) in relation to haematological and biochemical parameters in male albino rats. M.Sc., Thesis, Girl's college, Ain Shams University.

54. Ronis, M.J.; Badger, T.M.; Shema, S.J. and Roberson, P.K. (1996): Reproductive toxicity and growth effects in rats exposed to lead at different periods during development. Toxicol Appl Pharmacol.; 136: 361-371.

55. Thareux-Manlav, A.; Velez-de la calle, J.F.; Olivier, M.F.; Soufir, J.C.; Masse, R. and Pinon-Lataillade, G. (1995): Impairment of testicular endocrine function after lead intoxication in the adult rat. Toxicology, 100(13): $101-109$.

56. Acharya, U.R.; Mishra, N. and Acharya, S. (1997): Effect of lead acetate on male germinal cells of Swiss mice. Cytologia 62, $231-236$.

57. Ronis, M.J.; Gandy, J. and Badger, T. (1998): Endocrine mechanisms underlying reproductive toxicity in the developing rat chronically exposed to dietary lead. Journal of Toxicology and Environmental Health 54, 77-99.

58. Godeas, C.; Tramei, F; Sandri, G. and Panfili, E. (1999): Rat testis mitochondrial phospholipids hydroperoxide glutathione peroxidase does not protect endogenous vitamin $\mathrm{E}$ against $\mathrm{Fe} 2+$ induced (lipo) peroxidation. Biochem. Mol. Med. 58(2): 221 - 227. 
59. Edrees, M.A. (2006): Sensitivity of lead and cadmium exposure on some constituents of blood and testicular functions in the male rats and the therapeutic role of vitamin $\mathrm{C}$ or zinc and their mixture supplementation. M.Sc., Thesis, Girl's college, Ain Shams University.

60. Pascoe, G., Olafsdottier, F., Read, D., 1987. Vitamin E protection against chemical-induced cell injury. I. Maintenance of cellular protein thiols as a cytoprotective mechanism. Arch. Biochem. Biophys. 256, $150-158$.

61. Aldana, L., Tsutsumi, V., Craigmill, A., Silveira, M.I., De Mejia, E.G., 2001. a-Tocopherol modulates liver toxicity of the prethroid cypermethrin. Toxicol. Lett. 125, 107-116.

62. John, S., Kale, M., Rathore, N., Bhatnagar, D., 2001. Protective effect of vitamin E in dimethoate and malathion induced oxidative stress in rat erythrocytes. J. Nutr. Biochem. 12, 500-504.

63. Agarwal, R., Goel, S.K., Chandra, R., Behari, J.R., 2010. Role of vitamin E in preventing acute mercury toxicity in rat. Environ. Toxicol. Pharmacol. 29, 70-80.

64. Yang, H.S., Han, D.K., Kim, J.R., Sim, J.C., 2006. Effects ofatocopherol on cadmium-induced toxicity in rat testis and spermatogenesis. J. Korean Med. Sci. 21, 445-451.

65. Osfor, M.M.H., Ibrahim, H.S., Mohamed, Y.A., Ahmed, A.M., Abd El Azeem, A.S., Hegazy, A.M., 2010. Effect of alpha lipoic acid and vitamin E on heavy metals intoxication in male albino rats. J.Am. Sci. 6, 56-63.

66. Beytut, E., Yuce, A., Kamiloglu, N.N., Aksakal, M., 2003. Role of dietary vitamin E in cadmium-induced oxidative damage in rabbit's blood, liver and kidneys. Int. J. Vitam. Nutr. Res. 73, 351-355.

67. Ognjanovic’, B.I., Pavlovic', S.Z., Maletic', S.D., Zikic', R.V., Stajn, A.S., Radojicic', R.M., Saic ic', Z.S., Petrovic, V.M., 2003. Protective influence of vitamin E on antioxidant defense system in the blood of rats treated with cadmium. Physiol. Res. 52, 563-570.

68. Hassan, N.S., Awad, S.M., 2007. Reverse effect of vitamin E on oxidative stress, derivatives and conductivity changes of hemoglobin induced by exposure to cadmium. J. Appl. Sci. Res. 3, 437-443.

69. Church, D.C. and Pond, W. G. (1988): "Basic Animal Nutrition and Feeding" 3rd ed. John Wiley \& Sons, New York, U.S.A. Pp. 190.

70. Hidiroglou, M.C.; Williams, J.; Ho, S.K. and Tryphonas, L. (1978): Role of uptake zinc on male reproductive system of rats. Am. J. Vet. Res., 40: 103.

71. Hesketh, J.E. (1982): The role of zinc on male reproductive functions in rats. J. Comp. Physiol., $92: 239-247$.

72. Hunt C.D.; Johnson, P.E.; Herbl, J. and Mullen, L.K. (1992): Effect of short term zinc administration on serum testosterone concentrations in young men. Am. J. Clin. Nutr., 56: $148-157$.

73. Eder, K. and Kirchgessner, M. (1997): Concentrations of lipids in plasma and lipoproteins and oxidative susceptibility of low-density lipoproteins in zinc-deficient rats fed linseed oil or olive oil J. Nutr. Biochem., 8: 461 - 468.

74. Cao, G. and Chen, J. (1991): The role of some antioxidant on lipid peroxidation status.Arch. Biochem. Biophys., 291: $147-153$.

75. Sullivan, J.F.; Jetton, M.M.; Hahn, H.K.J. and Burch, R.E. (1980): Enhanced lipid peroxidation in liver microsomes of zinc-deficient rats. Am. J. Clin. Nutr., 33: 51 - 56.

76. Koo, S.I. and Turk, D.E. (1977): Effect of zinc deficiency on the ultra-structure of the pancreatic acinar cell and intestinal epithelium in the rat. J. Nutr., 107: $909-919$.

77. Koo, S.I.; Norvell, J.E.; Algilani, K. and Chow, J.J. (1986): Effect of marginal zinc deficiency on the lymphatic absorption of [14C] cholesterol. J. Nutr.; 116:2363 - 2371.

78. Durá-Travé, T.; Puig Abuli, M.; Monreal, I. and Villa-Elizaga, I. (1986): Plasmatic zinc concentrations during pregnancy in zinc-deficient rats in relation to neonatal outcome. Gynecol. Obset. Invest, 22: 134 - 139.

79. Morley, J.E.; Gordone, J. and Hershman, J.M. (1980): Zinc deficiency, chronic starvation, and hypothalamicpituitary-thyroid function. Am. J. Clin. Nutr, 33: 1767 - 1770. 